\title{
Libertad de conciencia y culto: una mirada a la realidad colombiana"
}

\author{
Viviana Ramirez Alfonso**
}

Recibido: 25 de febrero de 2016 • Aprobado: 1 de abril de 2016

\section{Resumen}

El presente artículo analiza los derechos a la libertad de conciencia y culto a la luz de la separación, desde el año 1991, del estado colombiano con la iglesia. Lo anterior porque las creencias y convicciones religiosas son propias del "ser", integran su identidad y en el curso de la vida diaria recaen en el "hacer", lo que ha derivado en el nacimiento de una censura pública al criterio y al actuar de aquel que, declarada o no, tiene una convicción religiosa. No son entonces la conciencia, las convicciones religiosas o los principios de vida, elementos de quitar y poner en el ejercicio de la vida académica, laboral, política o social y merecen por ende todo el respeto de la sociedad en general.

Palabras clave: libertad, religión, conciencia, culto, ser, hacer.

* Escrito producto de las investigaciones de la autora.

* Abogada, Especialista en Derecho Penal de la Universidad Católica de Colombia y Magíster en Derecho con énfasis de Derechos Humanos y Derecho Internacional Humanitario de la Universidad Sergio Arboleda. Asesora de la Procuraduría General de la Nación, Colombia. Correo electrónico: Viviramirezacademic@gmail.com 


\title{
Freedom of conscience and religion: a look at the colombian reality
}

\begin{abstract}
This article analyzes the rights to freedom of conscience and religion in the light of the separation the church and Colombian state, since 1991. Moreover, the religious beliefs and convictions are those of the "being" of a person, integrating their identity, while, the course of everyday life falls into the "doing". This has resulted in the birth of a public censure based on the criteria and action of whom, whether declared or not, has a religious conviction. Therefore, the consciousness, religious beliefs or principles of life, are not elements to be removed, but rather to be put in the exercise of academia, labor, politics and social life and thus deserve all the respect in society in general.
\end{abstract}

Keywords: Freedom, religion, conscience, religion, being, doing.

\section{Liberté de conscience et de culte: un regard à la réalité colombienne "}

\section{Résumé}

Cet article analyse les droits à la liberté de conscience et de culte à la lumière de la séparation, depuis 1991, de l'état colombien et de l'église. Cela parce que les croyances et les convictions religieuses sont propres de $\mathrm{l}^{\prime}$ " être », parce qu'elles intègrent son identité et dans le cours de la vie quotidienne retombent dans le "faire », ce qui a dérivé dans la naissance d'une censure publique face au critère et à l'agir de celui qui a une conviction religieuse, déclarée ou non. La conscience, les convictions religieuses ou les principes de vie, ne sont donc pas des éléments à mettre ou à enlever dans l'exercice de la vie académique, professionnelle, politique ou sociale et méritent par conséquent tout le respect de la société en général.

Mots-clés: Liberté, religion, conscience, culte, être, faire. 


\section{Introducción}

Colombia es un país pluralista en el cual desde la Constitución Política se ha consagrado la protección a las personas y sus derechos. Hoy se predica con fuerza que los colombianos tenemos derecho a la libertad de conciencia y a la libertad de cultos, como derechos del más alto rango y dignos de la mayor protección. Pero, una vez están con claridad descritos en el papel estos derechos junto con su significado y alcance, suele pensarse que se ha obtenido de esta forma la validez y protección eficaz de los mismos, al permanecer incólumes y respetados por todos aquellos que nos rodean.

Sin embargo la realidad colombiana es un poco distante del deber ser en cuanto a los derechos a la libertad de conciencia y culto, ello porque la íntima convicción personal de cada sujeto ha tomado un rumbo silencioso, y es obligada a transitar por un camino de anonimato social que nos grita que la convicción religiosa es tan, pero tan personal, que no debe si quiera mencionarse, exteriorizarse o ser conocida por los demás.

Se afirma lo anterior porque cuando por error, descuido, convicción o valentía, las personas exteriorizan sus convicciones religiosas en el ámbito académico, laboral o social, surge el automático "derecho" de los demás para señalar y tachar de sesgados, fanáticos o a veces falsos, los principios con los que se rige esa vida laboral, familiar y personal para generar una descalificación de la persona en su hacer diario.

Se ha creado alrededor de las convicciones religiosas una cortina de humo tan densa, que incluso el tener posiciones en favor de la vida y contra el aborto es prohibido para quienes han exteriorizado sus convicciones. Frente a ello es necesario analizar si aquel que rige su vida desde los principios o dogmas de una religión, puede separar aquello de los principios que orientan su actuar y con los que ejerce todas las actividades diarias, o si las convicciones que cada persona tiene, la acompañan y hacen parte de su identidad en el medio social, independientemente del cargo o responsabilidad que ostente. Asimismo cabe la duda, respecto de aquel que es ateo o no practica religión alguna y de si ello se separa de su ejercicio diario. Surge entonces el siguiente interrogante: ¿Estado laico o estado aconfesional, implica, impone o determina individuos carentes de sentimiento religioso?

Por ello, a través de este texto se hará un breve recuento de los antecedentes más recientes del reconocimiento constitucional de los derechos a la libertad de conciencia y culto, se identificará la incorporación de estos derechos a nivel 
constitucional y legal, para luego analizar, bajo las premisas del estado laico, la relación entre el individuo, su conciencia y su actuar en sociedad. Adicionalmente se acudirá a la interpretación y alcance jurisprudencial ${ }^{1}$ constitucional de la libertad religiosa, de conciencia y culto para culminar con la cita de algunos ejemplos de la realidad colombiana que reflejan la necesidad de los argumentos planteados.

\section{Antecedentes}

La Constitución Política de Colombia nos da elementos claves con respecto a la posición de nuestro Estado frente a la libertad religiosa, e incluso frente a las iglesias en general. Lo anterior porque justamente fue la Asamblea Nacional Constituyente, integrada por miembros de diferentes creencias y corrientes políticas ${ }^{2}$, la que pese a un abstencionismo aproximado del $75 \%$ de los votantes, reflejó algo de la pluralidad de nuestro país para el año 1991, lo que derivó en una Carta que en extenso se dedicó a incluir y resaltar los derechos que tenemos los colombianos y las formas y mecanismos de protección de los mismos.

El Preámbulo de la Constitución, que es aquél acápite contentivo de la declaración inicial y previa al articulado, no solo hace parte integral del texto constitucional, sino que, como lo ha señalado la jurisprudencia de la Corte Constitucional (C-477/05, 2005) goza también de fuerza vinculante, ya que señala los principios

1 Jurisprudencia: Del lat. iuris prudentĭa. (Española, 2016). Una definición más clara y actual: "[...] solución sugerida por un conjunto de decisiones suficientemente concordantes, emitidas por las jurisdicciones acerca de una cuestión de derecho". (Guillen \& Vicent, 2008) En nuestro ordenamiento jurídico colombiano, puede entenderse como el conjunto de aquellas decisiones de cierre que emiten las altas cortes, a través de las cuales pueden decidir en casos determinados, para efectuar interpretación de los derechos y el alcance que tienen. Se destaca para este escrito aquella jurisprudencia proveniente de la Corte Constitucional respecto de la cual dicha Corporación ha dicho: "Tratándose del tribunal constitucional, la fuerza vinculante de la jurisprudencia de la Corte Constitucional tiene una doble fundamentación, en razón del órgano que la profiere: (i) de un lado, se trata del órgano de cierre de la jurisdicción constitucional; (ii) de otro lado, es el guardián de la "supremacía e integridad" de la Carta Fundamental." (C-816/11, 2011).

2 La Asamblea Nacional Constituyente fue elegida el 9 de diciembre de 1990 y se integró por 19 miembros de La Alianza Democrática M-19, 24 delegatarios integrantes del Partido Liberal, 11 escaños para El Movimiento de Salvación Nacional (Alzate, 2011). Estos integrantes son los más mencionados en los textos, sin embargo también la Asamblea se integró por 9 conservadores, 2 líderes del movimiento Unión Cristiana, 2 militantes de la Unión Patriótica y 2 curules para los Movimientos Indígenas. 
orientadores de las normas específicas contenidas en la Carta. ${ }^{3}$ De allí que al dar una mirada al preámbulo de la Constitución (1991), es posible identificar cómo al decretar, sancionar y publicar el texto, se invocó allí la protección de Dios, de la siguiente manera:

EL PUEBLO DE COLOMBIA, en ejercicio de su poder soberano, representado por sus delegatarios a la Asamblea Nacional Constituyente, invocando la protección de Dios, y con el fin de fortalecer la unidad de la Nación y asegurar a sus integrantes la vida, la convivencia, el trabajo, la justicia, la igualdad, el conocimiento, la libertad y la paz, dentro de un marco jurídico, democrático y participativo que garantice un orden político, económico y social justo, y comprometido a impulsar la integración de la comunidad latinoamericana, decreta, sanciona y promulga la siguiente CONSTITUCION POLITICA DE COLOMBIA [...]. (Constitución Política de Colombia, 1991)

Lo anterior nos lleva a identificar en nuestra Carta Magna un reconocimiento de Dios, de Su ser y de Su capacidad de protección frente al pueblo colombiano al promulgar la norma guía para nuestro país, con sus necesidades y carencias. Además de ello, el que se haya invocado en general aquella protección de Dios, marca el rutero de lo que es la libertad religiosa en el Estado colombiano, al identificar a las religiones como iguales, ninguna con preeminencia para el Estado, independientemente de su tamaño, antigüedad o costumbres, lo que va acompañado de un reconocimiento de la importancia de los sentimientos religiosos, por lo que se colige del preámbulo que el Estado no es indiferente al sentimiento religioso que puedan tener muchos de sus asociados.

3 “El Preámbulo da cuenta del sentido político y jurídico que el Pueblo de Colombia le imprimió a la formulación de la Carta Política de 1991; es decir, indica los principios que la orientan y los fines a cuya realización se dirige y por ello no sólo hace parte de ésta como sistema normativo sino que además tiene efecto vinculante sobre los actos de la legislación, la administración y la jurisdicción y constituye parámetro de control en los procesos de constitucionalidad. Y esto es comprensible pues carecería de sentido que una fórmula política y jurídica tan densa de contenidos como la advertida en el Preámbulo, no estuviera llamada a tener implicaciones en los ejercicios de poder subordinados a la teleología en ella señalada." (C-477/05, 2005) 


\section{Protección constitucional y legal a la libertad de conciencia y culto}

En la Constitución Política de Colombia de 1991, como carta de navegación de derechos en nuestro país, ubicamos el derecho fundamental a la igualdad (Art. $13)^{4}$ en el que se consagra aquella calidad de iguales que tenemos todas las personas frente a la ley, la que es la base del reconocimiento de la individualidad y de la capacidad de determinación de vida en el marco de la protección del Estado. De ahí que explícitamente el factor religioso se haya incluido y mencionado como protegido frente a cualquier forma de discriminación.

En consecuencia el Texto Constitucional consagró en los artículos 18 y 19 la garantía a las personas en sus convicciones, creencias o sentimientos afines a una religión, así:

Artículo 18. Se garantiza la libertad de conciencia. Nadie será molestado por razón de sus convicciones o creencias ni compelido a revelarlas ni obligado a actuar contra su conciencia.

Artículo 19. Se garantiza la libertad de cultos. Toda persona tiene derecho a profesar libremente su religión y a difundirla en forma individual o colectiva.

Todas las confesiones religiosas e iglesias son igualmente libres ante la ley. (Constitución Política de Colombia, 1991)

La Constitución es absolutamente clara al ubicar como derechos fundamentales y resaltar la enorme preeminencia que tienen en la vida del ser humano, sus íntimas convicciones y, en caso de haber optado por ella, la religión que se decida profesar.

Posteriormente la ley 133 de 1994 dio desarrollo al Derecho de Libertad Religiosa y de Cultos, reconocido en el artículo 19 de la Constitución Política y en su artículo primero consagró: “El Estado garantiza el derecho fundamental a la libertad religiosa y de cultos, reconocido en el artículo 19 de la Constitución Política. Este derecho

4 "Artículo 13. Todas las personas nacen libres e iguales ante la ley, recibirán la misma protección y trato de las autoridades y gozarán de los mismos derechos, libertades y oportunidades sin ninguna discriminación por razones de sexo, raza, origen nacional o familiar, lengua, religión, opinión política o filosófica. El Estado promoverá las condiciones para que la igualdad sea real y efectiva y adoptará medidas en favor de grupos discriminados o marginados. [...]" (Constitución Política de Colombia, 1991) 
se interpretará de conformidad con los tratados internacionales de derechos humanos ratificados por la República." (Ley 133/94, 1994)

La ley describe y desarrolla los derechos mencionados en los ámbitos sociales, como el establecimiento de lugares de culto, el profesar privada y públicamente la religión que se practique, el cumplimiento de actividades relacionadas con la educación, la regulación frente a personerías jurídicas y la autonomía de las iglesias y confesiones religiosas, entre otras.

Es importante por último, reseñar que en virtud al bloque de constitucionali$\operatorname{dad}^{5}$ y de conformidad al artículo 93 Superior $^{6}$, instrumentos internacionales como la Declaración Universal de Derechos Humanos ${ }^{7}$, la Convención Americana de Derechos Humanos o Pacto de San José de Costa Rica ${ }^{8}$, entre otros, han consagrado la garantía e importancia que tienen los derechos de conciencia y religión, y su preeminencia por estar directamente ligados a la persona y su dignidad.

\section{Estado laico -sentido jurídico-}

Hay una realidad en Colombia y es que el término Estado laico ha "hecho carrera", si es que puede usarse esta expresión, de forma que es ampliamente usado en sectores sociales, políticos y académicos. Pero, ¿consagra la Constitución Política de Colombia de 1991 en su texto que Colombia es un Estado laico? La respuesta

5 La Corte Constitucional determinó que nuestra Carta Política se integra por todos sus artículos así como por los tratados internacionales e interpretación de los mismos ratificados por Colombia, lo que da lugar al denominado Bloque de Constitucionalidad, en el que los tratados de Derechos Humanos están en el mismo nivel que el articulado constitucional, es decir hacen parte de la Constitución. (C-225/95, 1995)

6 Artículo 93. "Los tratados y convenios internacionales ratificados por el Congreso, que reconocen los derechos humanos y que prohíben su limitación en los estados de excepción, prevalecen en el orden interno. Los derechos y deberes consagrados en esta Carta, se interpretarán de conformidad con los tratados internacionales sobre derechos humanos ratificados por Colombia." (Constitución Política de Colombia, 1991)

7 Artículo 18. "Toda persona tiene derecho a la libertad de pensamiento, de conciencia y de religión; este derecho incluye la libertad de cambiar de religión o de creencia, así como la libertad de manifestar su religión o su creencia, individual y colectivamente, tanto en público como en privado, por la enseñanza, la práctica, el culto y la observancia". (Declaración Universal de Derechos Humanos, 1948)

8 Artículo 12. Libertad de Conciencia y de Religión. "1. Toda persona tiene derecho a la libertad de conciencia y de religión. Este derecho implica la libertad de conservar su religión o sus creencias, o de cambiar de religión o de creencias, así como la libertad de profesar y divulgar su religión o sus creencias, individual o colectivamente, tanto en público como en privado". (Convención Americana de Derechos Humanos, 1978 *entró en vigencia) 
es sencilla, taxativamente no, sin embargo, es el mismo preámbulo analizado en precedencia, el que nos permite hacer una primera aproximación al hecho de que en nuestro país no hay una religión o iglesia que sea oficial del Estado.

En consonancia con lo anterior, la Corte Constitucional en decisión de tutela del año 2014 concluyó con base en los pronunciamientos hechos por esa Corporación en precedencia que “i) el Estado colombiano tiene un carácter laico, por lo cual es neutral frente a la promoción de las diferentes religiones que existen en el país. De tal manera, se logra asegurar el pluralismo, la coexistencia igualitaria y la autonomía de las distintas confesiones religiosas [...]"' (T-778-14, 2014)

De allí que podamos analizar que los términos laico o laicidad ${ }^{9}$, desde una perspectiva actual y jurídica, denotan independencia y neutralidad, así como lo señaló Vicente Prieto (2011) en su texto Estado laico y libertad religiosa antecedentes y desarrollos de la constitución colombiana de 1991 debe entenderse con toda claridad el significado que adquiere al respecto la palabra separación, pues tanto el Estado como la iglesia son sujetos distintos que en virtud a la laicidad, se separan. (Prieto, 2011)

Es así entonces como el Estado debe ser autónomo frente a las confesiones religiosas, lo que implica su caracterización como Estado aconfesional y por ende éste no tiene una religión oficial. Ahora, el Estado colombiano por su naturaleza laica, ha regulado como ya se vio el ejercicio de los derechos asociados a las convicciones de conciencia y religiosas que las personas escojan, lo que hace plenamente válido el respeto y garantía del ejercicio de los derechos de libertad de conciencia y culto.

Sin embargo, pese a la claridad de estas precisiones, suele asumirse la expresión "Estado laico" como un señalamiento enfocado a limitar el ejercicio de los derechos a la libertad religiosa y de conciencia de las personas, al desconocer que el principio de laicidad dentro de los Estados “...responde al reconocimiento de la bondad o de la necesidad histórica de crear espacios políticos y jurídicos libres y autónomos respecto a la guía religiosa o clerical." (Pele, Celador \& Garrido, 2010: p. 277).

Por ello no puede nunca confundirse un Estado laico con personas laicas, como si la laicidad del Estado diera el aval para requerir de los colombianos independencia o neutralidad frente a una $\mathrm{u}$ otra iglesia o impulsara una carencia total de sentimiento religioso.

9 “(...)2. f. Principio que establece la separación entre la sociedad civil y la sociedad religiosa. (RAE, 2016) 
Y el punto aquí es que, el hecho de que el Estado colombiano sea laico no significa que su actitud frente al sentimiento religioso de las personas sea indiferente o displicente, por el contrario, es el artículo 2 de la ley estatutaria de libertad religiosa que consagra ese derecho de creer y regir la vida de acuerdo a esas creencias, lo dice de esta manera: "Ninguna Iglesia o Confesión religiosa es ni será oficial o estatal. Sin embargo, el Estado no es ateo, agnóstico, o indiferente ante los sentimientos religiosos de los colombianos. (...)" (Ley 133/94, 1994) Es de suma importancia saber que el Estado reconoce que no es ateo, por lo que mal podría pretenderse que todas las personas ostenten tal ateísmo o carezcan por completo de religión alguna o de la libertad de profesar la que hayan decidido tener.

$\mathrm{Al}$ respecto es pertinente analizar que en desarrollo de los debates de la Asamblea Nacional Constituyente que dieron origen a nuestra Constitución, se analizó una proposición aditiva del siguiente tenor: "El ejercicio del ministerio sacerdotal y pastoral de cualquier religión o culto es incompatible con las funciones públicas" (Cepeda, 1994: p. 46) tal proposición no fue aprobada y claramente denotaba una limitación desproporcionada para el ejercicio simultáneo de dos actividades que pueden converger en una misma persona, sin que sean excluyentes entre sí.

Sin embargo esta proposición pareciera que tácitamente hubiera sido implementada socialmente, al punto que hay un claro sesgo hacía los planteamientos de quien, o ejerce un ministerio sacerdotal o pastoral, o profesa firmemente los dogmas de su religión, y a la vez ocupa cargos o realiza funciones de alto impacto social.

Surge aquí una cuestión eminentemente ontológica que nos permite preguntarnos: ¿Qué lugar ocupan en la vida de las personas los mandatos que le dicta su conciencia? y ¿Qué lugar ocupa en la vida de las personas la religión?

$\mathrm{Al}$ respecto puede analizarse el concepto de identidad desde la perspectiva de lo dicho en el libro Identidad chilena por Jorge Larraín (2001: p. 21): “El principio ontológico de identidad o de «no contradicción» afirma que todo ser es idéntico consigo mismo y, por lo tanto, una cosa no puede ser y no ser al mismo tiempo y desde un mismo punto de vista.". De ahí que la persona no pude negarse a sí misma ni actuar contra todos los factores que determinan su "ser".

Como seres humanos desde nuestra concepción estamos expuestos a condiciones y situaciones que con el pasar del tiempo influencian nuestra vida y hacen parte de ese constructo de calidades, cualidades, habilidades, creencias, valores, entre otros, que representan lo que somos.

En medio de la cantidad de factores, enunciados o no, se encuentra uno relevante a tocar en esa oportunidad, como lo es la religión y las convicciones de las personas, muy claro lo expresaron Tunal, G. y Camarena, M. en su artículo del 
año 2009 denominado "La religión como una dimensión de la cultura" cuando indicaron que "La religión acompaña al hombre y a la sociedad como un elemento básico de la composición del individuo y de su propia identidad (...)" (Tunal \& Camarena, 2009). Desconocer entonces que las convicciones y la conciencia de las personas deben dejarse en casa al salir a las actividades diarias, es deconocer el mínimo respeto por la dignidad del ser humano y de su identidad, que es la que determina su hacer, sin ella, sin sus valores y reglas, las personas careceríamos de códigos propios e individuales para afrontar la vida diaria.

Ahora, se resalta que la fe juega un papel importante en lo que somos y por ende también en lo que hacemos, al respecto Tunal, G. y Camarena, M. (2009) afirmaron:

A través del acto de la fe es que el fenómeno de la actividad religiosa se va a fundamentar debido a que la creencia de manera casi absoluta de los estamentos religiosos es lo que va a constituir el centro mismo de las expresiones cotidianas. Por medio de los textos sagrados o del habla, se va a formar una parte importante de las características definitorias de la identidad de una sociedad, es decir, de la cultura que se posee. (Tunal \& Camarena, 2009: p. 7)

Las expresiones cotidianas no pueden ser otra cosa que la exteriorización de la esencia de cada persona; es decir, nuestro ser determina nuestro hacer, por lo que esperar que nuestro ser sea escondido e ignorado en el ejercicio de nuestro hacer es propender por un dualismo, en el que la fe, la espiritualidad, la conciencia o la religión se convertirían en un "sombrero" de quitar y poner.

Para citar un ejemplo, podemos ver que el tema de la construcción de políticas públicas está directamente relacionado con las convicciones o creencias de las personas, de allí que quien no prioriza el valor de la persona y la afectación que puede causarle el consumo de sustancias psicoactivas en su vida, hace que se busquen políticas promotoras del consumo en aras del "respeto" por el libre desarrollo de la personalidad. ¿No es acaso irónico decirle a una persona que goza del libre desarrollo de su personalidad y que por esa razón el Estado le proveerá los medios para que acuda o consuma drogas como una opción viable, cuando esto, aunque libre de ser seleccionado por cada persona, al final del tiempo, la destruirá?

El análisis se centra entonces en lo que conforma el ser y cómo ello determina el hacer, por lo que el hacer nunca es producto de la nada, el hacer es producto del ser y por ende la religión, las convicciones y la conciencia, necesariamente juegan un rol en el desempeño diario de las personas, si influyen y si intervienen. Entonces el punto es, ¿por qué ello es malo, por qué ello no es valorado o 
permitido, por qué es juzgado como una "mezcla" indeseada de religión y política, o de religión y academia, o de religión y vida laboral?

El hecho de que una persona rija su vida bajo los principios de una religión, no siempre se relaciona con que sus posiciones sean imponer su criterio a los demás, es así que jurídicamente pueden regularse determinados temas de relevancia social, que muchos suelen interpretar como de contenido religioso, para ejemplificar esto, se trae a colación lo dicho por Prieto (2011: p. 122) quien afirmó que el hecho de que la legislación colombiana tenga consagrado el delito de aborto, no tiene su razón de ser en un sentimiento, criterio o imposición religiosa, por el contrario surge del derecho constitucional a la vida y del deber del Estado de proteger ese derecho.

Muchas veces los principios o valores religiosos, por su propia naturaleza en búsqueda del bien ${ }^{10}$ coinciden y se armonizan con los principios y valores apropiados y útiles para la vida en sociedad, por lo que no puede desconocerse que la religión ha hecho innumerables aportes a la humanidad y a la sana convivencia.

Todo lo anterior nos permite concluir que no puede equipararse nunca la laicidad del Estado a las personas, ni habilita para pedir de ellas un ejercicio carente de sentimiento religioso en su vida tanto pública como privada, ya que la religión como elemento integrante de la identidad no puede negarse y determina el ejercicio del diario vivir.

\section{Alcances e interpretación jurisprudencial de la libertad religiosa, de conciencia y culto.}

La jurisprudencia colombiana constitucional, a través de sus decisiones, ha dado algunos parámetros útiles relacionados con el ejercicio al derecho de la libertad de conciencia y culto, al resolver casos en los cuales estos derechos han pugnado con otros. Se enunciarán algunas de las decisiones más relevantes para el asunto tratado. Esto para hacer un recorrido por la evolución argumentativa de la Corte frente a la interpretación de los derechos a la libertad religiosa, conciencia y culto.

En primer lugar tenemos una sentencia emitida en el año 1993 cuyo Magistrado Ponente (M. P.) fue Carlos Gaviria Díaz y la que analizó un choque de derechos con respecto a la autonomía universitaria y a la libertad de cultos y en la que la Corte estimó que:

10 Puede que en algunas religiones no sea de esta manera, cito para el caso religiones mayoritarias y ampliamente reconocidas y practicadas. 
[...] Si toda libertad encuentra su límite en el derecho y en la libertad del otro, el militante de una fé (sic) tiene que ser consciente de que ha de conciliar las prescripciones que de ésta deriva, con las que tienen su origen en la norma jurídica válidamente establecida y que si opta por las primeras, ha de afrontar las consecuencias que se siguen de su elección, sin que éstas puedan ser juzgadas como injustas represalias por la adhesión a un determinado culto. (T-539a/93, 1993)

Este análisis hecho por la Corte refleja una actitud hostil frente al sentimiento religioso y distante de lo que la Constitución dos años atrás describió como libertad de conciencia y culto, ya que decirle al militante de una fe que sea consciente que debe conciliar sus prescripciones religiosas con las prescripciones legales, pero esa conciliación implica la renuncia a los dogmas de su convicción, es un detrimento y una clara desigualdad de quien cree, frente a quien no cree, ya que quien tiene una convicción debe entonces "enfrentar las consecuencias de dicha decisión", postulado que no se ajusta a la dignidad del ser humano y a su derecho a trascender sus convicciones de lo privado a lo público.

Esta decisión tuvo un salvamento de voto ${ }^{11}$ por parte del Magistrado Eduardo Cifuentes Muñoz, quien expresó su disenso con la decisión mayoritaria de la Corte al considerar que el derecho a la libertad religiosa ofrece mayor fuerza normativa que el derecho otro derecho en pugna (a la autonomía universitaria), fundado ello en el papel medular y principal que ocupa la persona, su dignidad y sus derechos con respecto a los que son otorgados a las instituciones y su estructura organizacional.

Este salvamento vino a ser la punta de lanza para la posterior interpretación que le dio la Corte al alcance del derecho a la libertad de conciencia y culto, por estar directamente relacionado con la persona y con su dignidad.

Más tarde la Corte, en una providencia cuyo M. P. fue José Gregorio Hernández Galindo, se pronunció y argumentó que en ejercicio del poder de salvaguarda de la Carta Política, al juez constitucional se le impone buscar la convivencia de todos los derechos fundamentales, para explicar además que la libertad religiosa solo puede hacerse realmente efectiva cuando:

11 El salvamento de voto en Colombia tiene su razón propia de ser en el estado social de derecho en el que la Constitución como norma superior tiene una salvaguarda, cual es la Corte Constitucional, en la que sus miembros no son solo integrantes que piensan en colectivo, sino que cada uno es dueño de su propio criterio y tiene la facultad de expresarlo cuando no es el mismo de la mayoría. 
[...] quien profesa unas ciertas creencias religiosas o unas determinadas convicciones morales tiene derecho a proclamarlas, a difundirlas, a defenderlas, a practicar lo que de ellas se desprende, y a la inalienabilidad de su propia esfera de pensamiento, de modo tal que ni el Estado, ni los particulares, ni institución alguna puede invadirla para forzar cambios de perspectiva, ni para molestar o perseguir al sujeto por razón de aquéllas, ni para censurarlas, ni con el objeto de compelirlo a revelarlas, y menos con el fin de obligarlo a actuar contra su conciencia (artículo 18 C. P.). (T-393/97, 1997)

Es posible identificar elementos claves en esta decisión, entre ellos que parte integrante del derecho a la libertad religiosa es, no solo tener la convicción en secreto o en privado, sino poder exteriorizarla, difundirla, defenderla y, que ni particulares ni instituciones pueden molestar, perseguir o censurar a las personas por la existencia de tal convicción.

Luego en el año 1998 el Alto Tribunal Constitucional reiteró que la libertad religiosa no es solo tener una convicción, sino además que este derecho se hace extensivo a los actos externos por medio de los cuales se manifiesta tal convicción, y adicionalmente dijo:

[...] Particularmente, para el creyente la coherencia de su vida personal con los dogmas y creencias de su religión, reviste una importancia capital, hasta el punto de que ella es fuente de complacencia o de inmenso sufrimiento en el evento de que por cualquier razón ella no se logre alcanzar. (T-588/98, 1998)

La Corte entra entonces en el escenario de lo que es la persona, lo que integra su identidad y que el vivir la vida de acuerdo a sus convicciones es de la entraña de la dignidad humana, y puede generar tanto "complacencia" como "sufrimiento", por lo que esta decisión concluye, entre otras cosas, que no sería coherente garantizar en la Constitución la libertad religiosa, pero tampoco rehusarse a proteger las manifestaciones derivadas de la religión, ya que en ultimas la persona aspira a ser consecuente en la práctica con lo que cree.

Un año más tarde fue emitida la sentencia T-877 (1999), M. P. Antonio Barrera Carbonell, en la que se analizaron supuestos de hecho relacionados con la reverencia a los símbolos patrios y el hecho de que para los integrantes de la Iglesia de los Testigos de Jehová ello significa adoración, lo que es contrario a sus dogmas bajo los cuales la adoración solo se rinde a Dios. 
En esta oportunidad la Corte consideró que la exaltación de los símbolos de la patria no puede ser considerada como contraria a las convicciones religiosas, ya que en sí mismas, son importantes para el proceso educativo del estudiante y permiten que en él se desarrolle el sentimiento cívico consagrado constitucionalmente.

Esta decisión tuvo el salvamento de voto emitido por el Magistrado Eduardo Cifuentes Muñoz, quien indicó que:

[... las restricciones impuestas a la comunidad religiosa renuente no persiguen ninguno de los objetivos establecidos en la ley, pues la no participación en los actos de reverencia a los símbolos patrios no afecta el goce de los derechos constitucionales de otras personas; tampoco apareja problemas de salud o seguridad públicos y, mucho menos, afecta la moral pública. (T-877/99, 1999)

La ponderación hecha por el Magistrado es más que lógica, al no encontrar derechos de mayor fuerza normativa que la libertad religiosa, ni la afectación, con el respeto a la libertad religiosa, de los derechos constitucionales de otras personas.

Con posterioridad la Corte se pronunció en un caso relacionado con el aspecto laboral, sentencia T-982 (2001) y resolvió un conflicto derivado de la imposición a laborar durante el Sabbath para los integrantes de la Iglesia Adventista del Séptimo Día, estableció el Órgano de Cierre que la libertad religiosa “(...) no sólo tiene que ver con la posibilidad de que todo individuo tenga y desarrolle libremente un mundo espiritual propio. El texto constitucional confiere alcances sociales a dicha protección, al garantizar que se practiquen y realicen ciertos actos (...)" (T-982/01, 2001), estos en consecuencia relacionados con determinada creencia.

Para el año 2002 la Corte Constitucional señaló un elemento adicional de la libertad religiosa y es que también incluye el reconocimiento de quienes han decido no tener culto o religión determinada. (T-345-02, 2002) Por lo que aquel que rige su vida pública o privada desde el ateísmo o desde la ausencia de religión goza también del respeto a su libertad religiosa, y por ende a regir su vida bajo esos parámetros que se ha trazado.

Al continuar con el análisis, el Alto Tribunal reiteró (2005) que la convicción religiosa no hace parte exclusiva del fuero individual de la persona, sino que integra al ser, y a su vez implica su exteriorización, así:

La libertad religiosa, entonces, garantizada por la Constitución, no se detiene en la asunción de un determinado credo, sino que se extiende a los actos externos en los que éste se manifiesta. Particularmente para el 
creyente la coherencia de su vida personal con los dogmas y creencias de su religión, reviste una importancia medular, en tanto muchas veces ella determina los proyectos de vida personal. (T-026/05, 2005)

Y tiene una especial importancia esta decisión, cuyo M. P. fue Humberto Sierra Porto, por cuanto incluye ya los proyectos de vida personales como directamente influenciados por los principios o convicciones y por ende como elementos claves de la realización personal en escenarios como el académico, el laboral, el social o el político, ya que como se vio, el ser del creyente delimita su hacer, lo que no puede dividirse o separarse.

La Corte para el año 2007, en decisión cuyo M. P. fue Nilson Pinilla Pinilla, remarcó el hecho de que en el tema de la libertad religiosa y su consecuente comportamiento, el amparo a la libertad de conciencia y culto se da de dos formas “(...) no sólo con la protección de sus manifestaciones privadas, sino su ejercicio externo, sin desconocer que tiene límites en el ejercicio de las garantías públicas y los derechos fundamentales de los demás". (T-778-14, 2014)

Las posiciones anteriores fueron reiteradas en el 2011, cuando el Máximo Tribunal hizo un énfasis especial en aquello que afirmó en la citada decisión (analizada en este escrito) de tutela T-588/98, entre la coherencia que para el creyente debe existir entre los dogmas y creencias de su religión y su vida personal. Añadió que ello "Es parte del núcleo esencial de la libertad religiosa" (T-832/11, 2011) M. P. Juan Carlos Henao Pérez.

Otra decisión al respecto fue emitida en el 2014, en la cual se reiteró la posición de la Corte frente al alcance del derecho a la libertad religiosa, al comportar éste la posibilidad de exteriorizar las convicciones y no que solo permanezcan en el escenario privado, además de gozar del debido respeto al hacerlo y a no ser molestado, censurado o perseguirlo por divulgarlas, o por llevar su vida de acuerdo a sus dogmas. M. P. Jorge Ignacio Pretelt Chaljub (T-778-14, 2014).

En deciciones más recientes la Corte se ha mantenido en su posición así: "Como se ha dicho reiteradamente, la verdadera protección de la libertad religiosa implica la defensa de sus manifestaciones externas." (T-077-15, 2015)

Se puede concluir, que además de ser humanamente coherente la religión y la vida de las personas, también lo es jurídicamente y así en extenso lo ha reconocido la Corte Constitucional colombiana en ejercicio de sus funciones de órgano de cierre frente a circunstancias en las cuales los derechos a la libertad de conciencia y culto se han visto enfrentados a otros derechos. 


\section{Realidad colombiana -casos-}

Visto el basto panorama nacional en cuanto a la libertad religiosa y la interpretación de la misma, es del caso reseñar algunos casos de la vida nacional que nos permiten identificar la censura tácita al derecho a la libertad religiosa de conciencia y culto a la que se ha hecho referencia en este escrito.

Un primer caso es el del actual Procurador General de la Nación, Alejandro Ordóñez Maldonado, de quien abiertamente es conocida su filiación católica, al respecto se publicó en el portal web "Las 2 Orillas" un extenso documento en que se señalaba tal filiación religiosa y los antecedentes de la misma, con bastante desdén por demás, se enseñaron fotos del Procurador al salir de la Iglesia junto con su esposa, como quien aporta la prueba de un delito, además se dijo en ese entonces:

“Ocho años más tarde, y aunque reconocidos columnistas y periodistas se opusieron de tajo a su candidatura como procurador general de la Nación por su pasado camandulero, la sorpresa fue total al salir avante con una votación sin precedentes; 81 votos contra 1 , un cargo que ha venido ejerciendo de la mano de un Dios que invoca las 24 horas del día."

“Su talante, fortalecido por su devoción semanal, está presente en su trabajo de control disciplinario frente a los funcionarios públicos. Tal vez por ello no ha dudado en inhabilitar para ejercer cargos públicos a personalidades (...)" (Alejandro Ordóñez, un fanático religioso, 2013)

Este texto evidencia el brusco ataque por motivos religiosos a una persona que ostenta un cargo de autoridad en el país, ello porque el decir que hubo oposición de tajo por "su pasado camandulero"12 es irrespetar la dignidad de la persona, ya que la camándula ${ }^{13}$ como instrumento de la religión católica basado en el rosario y sus oraciones consecuentes, hace parte de la práctica y exteriorización de la convicción, por lo que ésta es un clara forma de descalificar a una persona por la opción que ha escogido en ejercicio de su libertad religiosa. Dejar en el ambiente además, que la razón por la cual el Máximo Jefe del Ministerio Público ha tomado

12 Camandulero, ra: de camándula. 1. adj. coloq. Hipócrita, astuto, embustero y bellaco. U. t. c. s. (RAE, 2016)

13 Camándula Tb. camándulas en acep. 3. de Camáldula, orden monástica fundada en el siglo XI en la Toscana. 1. f. Rosario de uno o tres dieces. U. m. en Am. (RAE, 2016) 
decisiones dentro de procesos disciplinarios, los que deben conservar un debido proceso y ajustarse a la norma disciplinaria vigente, es su talante fortalecido por su "devoción semanal", es asignar una carga negativa a la práctica religiosa.

En segundo lugar se trae a colación el caso del ciudadano Wílmar Gallo Alcaraz, quien al ser requerido para prestar el servicio militar indicó, entre otras cosas, su imposibilidad de hacerlo invocando la objeción de conciencia y su participación como miembro activo de la Iglesia Pentecostal Unida de Colombia, argumentos que no fueron tenidos en cuenta, y Wilmar recibió como respuesta por parte del Ejército Nacional, que su convicción no le excluía de prestar el servicio militar obligatorio y que en caso de no integrarse a las fuerzas militares, sería tenido como remiso.

Por ello Gallo Alcaraz ingresó al Batallón de Infantería № 32, Pedro Justo Berrio, el 12 de febrero de 2011 y sobre sus condiciones allí dijo a un periodista de El Espectador: "Cuando estoy solo, la tristeza me hiere y me pongo a llorar. Y me pregunto por qué estoy haciendo esto si yo no quiero. Portar armas es un agravio. Me tocó acostumbrarme porque evadirme habría sido infringir la ley."

Contó además, el hombre que pasó de ser civil a ser un soldado contra su conciencia, que varios comandantes fueron muy respetuosos con él y sus convicciones, pero también varios se burlaron de él diciéndole: "Evangélico, ahora sí te va a tocar matar, porque si no te matan". (La batalla de un cristiano contra el Ejército de Colombia, 2012)

En vista de la violación de sus derechos fundamentales, el soldado no tuvo otra opción que acudir a la Acción de Tutela, la que fue fallada por la Corte Constitucional en su favor en 2012, al ordenar al Ejército Nacional desincorporar a Wilmar si aún estaba en el batallón, bajo el argumento de que:

Para la Corte la objeción de conciencia de Wilmar Dario Gallo Alcaraz está relacionada con la convicción de la cultura de la no violencia, así como con creencias religiosas que aspiran a la paz y reprochan las circunstancias que ponen a un ser humano en la eventualidad de dañar a otro mediante el uso de las armas. Igualmente, se destaca un rechazo hacía la estructura castrense tanto a los medios de formación en estas instituciones como a la inminencia de hacer parte de la guerra cuando se es integrante de la fuerza pública. (T-018/12, 2012)

¡Es así como advirtió la Corte la especial condición de Wilmar Gallo y la forma como su permanencia como soldado del Ejército de Colombia era una violación a sus derechos de libertad de conciencia, culto y religión que debía cesar. 
Ese reconocimiento de la Corte a los derechos del soldado tuvo dos limitaciones prácticas. La primera fue que la decisión es del 20 de enero de 2012 y aún para la fecha del artículo periodístico, el 23 mayo 2012, Wilmar se encontraba en el batallón y patrullando el día anterior en una vereda de Frontino, Antioquia, es decir la violación de sus derechos continuó pese a una orden de la Corte.

La segunda fue que pasados 2 años del reconocimiento, la Corte Constitucional conoció de un recurso extraordinario de nulidad contra la acción de tutela mencionada, interpuesto por el Ministerio de Defensa Nacional, el que fue negado al argumentar que en efecto “(...) las razones para objetar conciencia del accionante fueron profundas, fijas y sinceras, y en esa medida, correspondía reconocerle este derecho a través del mecanismo constitucional." (A383-14, 2014)

Esta postura fue ratificada por la Corte en una reciente sentencia de 2015 en la cual resolvió un caso con supuestos fácticos similares, para proteger el derecho a la libertad de conciencia derivado de las convicciones religiosas. (T-185/15, 2015)

Un tercer ejemplo real y vívido en nuestro país, es el de Amada Rosa Pérez ${ }^{14}$, quien ha contado que al sufrir una crisis decidió acercarse a Dios, y el portal web KIENYKE.com al hacerle un reportaje dijo de ella: “Después de dejar el modelaje y la actuación, Amada Rosa Pérez se dedicó a rezar. (...) Reza al levantarse, reza en la tarde y reza en la noche. Reza, reza y reza." ("Pensé en suicidarme", 2012)

Entre varios argumentos que contiene el artículo, es extraño pensar que una persona pase de ser modelo o actriz para dedicarse a rezar, incluso el mismo documento cuenta sobre su nueva vinculación laboral y las actividades que en ella realiza. No hay espacio para otra conclusión diferente a que estos argumentos van directamente relacionados hacia un ataque por motivos religiosos, ya que Amada Rosa decidió cambiar sus principios de vida para regirse por los dogmas de la religión que ha escogido, lo que no puede ser catalogado como "una nueva actividad" o que por practicar sus convicciones no se dedique a nada más sino solo a rezar.

\section{Conclusión}

En el recorrido hecho a lo largo de este documento sobre los derechos a la libertad de conciencia y culto, se sentaron las bases del verdadero significado del Estado laico colombiano, y se determinó que en ninguna medida ello puede significar

14 Modelo y actriz colombiana entre los años 1991 y 2007. 
que las personas deben separar sus convicciones de su vida en general o que deban ser indiferentes al sentimiento religioso, por el contrario las creencias y convicciones religiosas integran al "ser" y el constructo de la identidad que siempre se ve reflejada en el actuar de los colombianos, sin que ello avale la burla, la discriminación o el maltrato religioso. A su vez quien es ateo o carece de creencia en religión determinada goza igualmente de ese derecho a la libertad religiosa y a ejercer su vida con esos parámetros sin que deba ser molestado por ello.

Por ende la censura pública que ha tomado fuerza en el país frente a la persona que, ostentando un cargo en el escenario laboral, académico o social, bien en la esfera de lo público o lo privado, tiene una convicción religiosa, no es más que una violación agresiva a los derechos a la libertad religiosa de conciencia y culto, constitucional y jurisprudencialmente reconocidos, que no debe ser tolerada por la sociedad ni menguada frente a la capital afectación que genera a la persona, su dignidad, su entorno y su vida en general.

\section{Referencias}

A383-14, Solicitud de nulidad de la sentencia T-018 de 2012 (Corte Constitucional 04 de diciembre de 2014).

Abueta, H. (28 de junio de 2012). KIENYKE.com. En: http://www.kienyke.com/ historias/pense-en-suicidarme/. Recuperado: 31 de enero de 2016.

Alzate, J. C. (03 de julio de 2011). http://www.elespectador.com/., de El arduo camino de la Constituyente de 1991. En: http://www.elespectador.com/noticias/temadeldia/ el-arduo-camino-de-constituyente-de-1991-articulo-281784. Recuperado: 17 de diciembre de 2015.

C-225/95, Expediente No. L.A.T.-040 (Corte Constitucional 18 de mayo de 1995).

C-477/05, Expediente D-5465 (Corte Constitucional 10 de mayo de 2005).

C-816/11, Expediente D-8473 (Corte Constitucional 1 de noviembre de 2011).

Cepeda, M. J. (1994). La constitución que no fue. Bogotá: Ediciones Uniandes/El Áncora Editores.

Constitución Política de Colombia (1991).

Convención Americana de Derechos Humanos (Organización de Estados Amenricanos 18 de julio de 1978 *entró en vigencia).

Declaración Universal de Derechos Humanos (Organización de las Naciones Unidas -ONU- 10 de diciembre de 1948). 
Real Academia Española [RAE] (2016). Real Academia Española. En: http://www.rae. es/: http://dle.rae.es/?id=MeLsLcP. Recuperado: 5 de enero de 2016.

Guillen, R. \& Vicent, J. (2008). Diccionario Jurídico. Bogotá: Temis.

Hidalgo, W. A. (23 de mayo de 2012). EL ESPECTADOR. En: http://www.elespectador. com/noticias/judicial/batalla-de-un-cristiano-contra-el-ejercito-de-colombiaarticulo-348252. Recuperado: 12 de noviembre de 2015.

Larraín, J. (2001). Identidad chilena. Chile: LOM Ediciones.

Ley 133/94 (23 de mayo de 1994).

Olivares, D. (09 de diciembre de 2013). Las 2 Orillas. En: http://www.las2orillas.co/ alejandro-ordonez-fanatico-religioso/. Recuperado: 01 de diciembre de 2015.

Pele, A., Celador, O. \& Garrido, H. (2010). La laicidad. Madrid: Dykinson/Instituto de Derechos Humanos "Cartolomé de las Casas" Universidad Carlos III de Madrid.

Prieto, V. (2011). Estado laico y libertad religiosa antecedentes y desarrollos de la constitución colombiana de 1991. Colombia: Universidad de La Sabana.

T-018/12, Expediente T- 3147388 (Corte Constitucional 20 de enero de 2012).

T-026/05, Expediente T-924708 (Corte Constitucional 20 de enero de 2005).

T-077-15, Expedientes T-4.436.001 y T-4.549.977 (acumulados) (Corte Constitucional 22 de febrero de 2015).

T-185/15, Expediente T-4.620.606 (Corte Constitucional 17 de abril de 2015).

T-345-02, Expediente T-488841 (Corte Constitucional 09 de mayo de 2002).

T-393/97, Expedientes acumulados T-126556, T-127074, T-127974 y T-130538 (Corte Constitucional 19 de agosto de 1997).

T-448-07, Expediente T-1529248 (Corte Constitucional 31 de mayo de 2007).

T-539a/93, Expediente No. T-18258 (Corte Constitucional 22 de noviembre de 1993).

T-588/98, Expediente T-173807 (Corte Constitucional 20 de octubre de 1998).

T-778-14, Expediente T-4.411.383. (Corte Constitucional 17 de octubre de 2014).

T-832/11, Expediente T-3114102 (Corte Constitucional 03 de noviembre de 2011).

T-877/99, Expediente T-224945 (Corte Constitucional 08 de noviermbre de 1999).

T-982/01, Expediente T-459129 (Corte Constitucional 13 de septiembre de 2001).

Tunal, G. \& Camarena, M. E. (2009). La religión como una dimensión de la cultura.

Nómadas. Revista Crítica de Ciencias Sociales y Jurídicas. Servicio de Publicaciones, Universidad Complutense de Madrid, 7. 